\title{
ESPORTE-ESPETÁCULO NA ECONOMIA CRIATIVA: FUTEBOL E PROMOÇÃO CULTURAL PARA O DESENVOLVIMENTO
}

\section{SPORT-SPECTACLE IN THE CREATIVE ECONOMY: SOCCER AND CULTURAL PROMOTION FOR DEVELOPMENT}

\begin{abstract}
LUCAS DO MONTE SILVA
Acadêmico do curso de Direito na Universidade Federal do Rio Grande do Norte (UFRN). Bolsista do Conselho Nacional de Desenvolvimento Científico e Tecnológico (CNPq). Membro da Equipe Editorial da Revista Direito e Liberdade, publicada pela Escola da Magistratura do Rio Grande do Norte (ESMARN). Natal, Rio Grande do Norte, Brasil. lucasdomonte1@gmail.com
\end{abstract}

\begin{abstract}
Patrícia Borba Vilar Guimarães
Doutora em Recursos Naturais pela Universidade Federal de Campina Grande. Professora da Universidade Federal do Rio Grande do Norte (UFRN). Líder da Base de pesquisa em Direito e Desenvolvimento. Natal, Rio Grande do Norte,

Brasil.

patriciaborb@gmail.com
\end{abstract}

\begin{abstract}
RESUMO
0 presente artigo objetiva elaborar conceitos referentes ao tratamento do termo economia criativa, pluridimensionado, mas já bem institucionalizado, e relacioná-lo com a atividade desportiva, em especial, o futebol, que é ao mesmo tempo um símbolo cultural e atividade econômica de alta rentabilidade no mundo contemporâneo, por meio de pesquisa bibliográfica e do método hipotético-dedutivo. Tendo sido elevado à categoria de espetáculo de proporções globais e modalidade empresarial de alta rentabilidade, o futebol hoje se situa no patamar das atividades de maior projeção enquanto entretenimento e patrimônio cultural na maioria dos países ocidentais e a sua relação direta com os setores criativos da economia o qualificam como categoria de estudo nesse campo. À vista do panorama apresentado, tem-se como problemática dessa pesquisa analisar a contribuição do futebol para o desenvolvimento local, regional e mundial, a partir do seu campo intangível, ao auxiliar e, ao mesmo tempo, fazer parte da Economia Criativa.
\end{abstract}

Palavras-chave: Desenvolvimento; Economia Criativa; Esporte-espetáculo; Patrimônio Cultural.

\begin{abstract}
This article aims to develop concepts for the term creative economy, pluradimensional, but already well institutionalized, and to relate it to sports, especially soccer, which is both a cultural symbol and high profitable economic activity in the contemporary world, through literature review and the hypotheticaldeductive method. Once having been elevated to the category of a spectacle of global proportions and business mode of high profitability, soccer today is at the same level of biggest projection activities as entertainment and cultural heritage in most Western countries and its direct relationship to the creative sectors of the economy qualify it as a study category in this field. In view of the panorama presented, the study aims, as a problem, to analyze the contribution of soccer to local, regional and world development, from its intangible field, to assist and, at the same time, be a part of the Creative Economy.
\end{abstract}

Keywords: Development; Creative economy; Sportspectacle; Cultural heritage. 


\section{SUMÁRIO}

INTRODUÇÃO; 1 ECONOMIA CRIATIVA E OS DESDOBRAMENTOS EM TORNO DO FUTEBOL-ESPETÁCULO; 2 AS QUESTÕES INSTITUCIONAIS RECENTES DO FUTEBOL-EMPRESA; 2.1 Legislação, regulação e incentivos ao futebol no Brasil; 2.2 A governança corporativa como fator de promoção da atividade futebolística; 3 FUTEBOL E DESENVOLVIMENTO NO CONTEXTO DA ECONOMIA CRIATIVA; 4 CONCLUSÃO; REFERÊNCIAS.

\section{INTRODUÇÃO}

O Plano Nacional da Economia Criativa, documento do Ministério da Cultura que inaugurou as diretrizes da Economia Criativa como política pública no país, conceitua os setores criativos como as atividades produtivas que tem um ato criativo gerador de bem que possua dimensão simbólica determinante do seu valor, demonstrando a riqueza cultural, econômica e social em sua produção. O futebol com todo o seu potencial simbólico, nesse aspecto, caracteriza-se como importante elemento propulsor do setor criativo, ressaltado nessa função recentemente pela realização de Megaeventos Esportivos no Brasil, a exemplo da Copa do Mundo FIFA de 2014, dos Jogos Mundiais Indígenas e dos Jogos Olímpicos e Paraolímpicos de 2016.

Nesse sentido, qual a contribuição do futebol para o desenvolvimento local, regional e mundial? Como situar o futebol-espetáculo como atividade criativa e incorporar benefícios dessa categorização no campo do intangível, em busca do desenvolvimento sustentável? Das relações entre estas prerrogativas de análise se situam alguns dos aspectos aqui colocados.

No segmento desportivo, tradicionalmente, o Brasil é associado ao futebol, assim como o Canadá é relacionado ao Hóquei. O futebol americano, o basquete e o baseball, por sua vez, são associados aos Estados Unidos. O Ping-Pong é visto como esporte, predominantemente, dos países asiáticos. 0 Rugby é relacionado à Nova Zelândia e à Austrália. 0 esporte, quer queira quer não, acaba por criar uma identidade para a sociedade da qual é mais praticado, seja a imagem elaborada correspondente a realidade ou não. Tal identidade, interiorizada pelo cidadão, acaba por fazer parte da cultura de cada sociedade. Isso pôde ser acompanhado recentemente na Copa do Mundo de 2014, na qual várias nações vieram ao Brasil participar do evento, de alcance mundial, tal como ocorreu nos Jogos Olímpicos de 2016, que ocorreram no Rio de Janeiro. 
O futebol integra o rol das atividades abrangidas pela Economia Criativa tanto pelo seu enorme papel simbólico, mundialmente reconhecido, como pela grande quantidade de conteúdo intangível produzido a partir dessa atividade, tais como design, propaganda, filmes, produtos de moda diversos, mídia televisiva, impressa e na internet, atividades turísticas e até mesmo produtos arquitetônicos, além de inovações tecnológicas variadas, considerados todos como diretamente ligados ao universo do entretenimento.

No Brasil, não são raras as reuniões nas quartas-feiras, sábados e domingos, para assistir partidas de futebol, discutindo sobre quem deverá ser campeão, quem merece o título, qual time será rebaixado, bem como também não são incomuns as "peladas" que ocorrem nos dias da semana, como atividade menos formalizada, mas que motiva milhares de pessoas. Esse fanatismo pelo futebol é passado por gerações, cada uma escolhendo o seu clube ou time favorito. Desde criança, os filhos (e vem crescendo o número de filhas) jogam futebol na “educação física”, são matriculados em escolinhas de futebol e incentivados à prática do esporte. O futebol indiscutivelmente faz parte da cultura brasileira e vem sendo cada vez mais situado como uma atividade que pode alcançar patamares de atividade econômica de alta rentabilidade num mercado cada vez mais profissionalizado.

Esse patrimônio cultural, ligado à indústria do entretenimento, pode ser situado como um motor no contexto contemporâneo da Economia Criativa, utilizada como referência analítica importante para o cenário do futebol midiatizado, espetacularizado, de base empresarial e fenômeno de alta rentabilidade.

À vista do panorama apresentado, tem-se como problemática dessa pesquisa analisar a contribuição do futebol para o desenvolvimento local, regional e mundial, a partir do seu campo intangível, ao auxiliar e, ao mesmo tempo, fazer parte da Economia Criativa.

Para o equacionamento do problema, levantou-se a seguinte hipótese: o futebol (e o próprio esporte, em geral) contribui para a economia criativa ao tempo que faz parte da identidade cultural da população brasileira. A economia criativa, por sua vez, é fundamental para os clubes de futebol, uma vez que figuras heroicas de outrora (investidores estrangeiros, milionários e bilionários que possuem times de futebol como hobby) diminuem cada vez mais, de forma que se mostra necessário a busca de alternativa de financiamento para os clubes, sobretudo considerando a Lei de Responsabilidade do Futebol Brasileiro.

Dessa forma, por meio de pesquisa bibliográfica e do método hipotético-dedutivo, buscou-se verificar essa hipótese mediante a investigação do tema de pesquisa em três seções.

Primeiramente, será analisada a relação entre a economia criativa e o seu modo de 
pensar em bens intangíveis com os desdobramentos do futebol-espetáculo, indo além de ser um esporte para se tornar uma "experiência" para o torcedor.

Em seguida, na segunda seção, objetiva-se discutir as questões institucionais recentes referentes ao futebol-empresa, analisando a legislação e regulação desse esporte, investigando os avanços legislativos e corporativos sobre a modernização do futebol em prol de uma verdadeira "governança corporativa" no futebol brasileiro.

Por fim, faz-se uma relação entre o desenvolvimento sustentável e o futebol, no contexto da economia criativa, demonstrando o pilar cultural e atrativo do esporte em uma nação.

\section{ECONOMIA CRIATIVA E OS DESDOBRAMENTOS EM TORNO DO FUTEBOL- ESPETÁCULO}

A noção de economia criativa pode ser entendida tanto como um modo de pensar a economia baseada em bens intangíveis quanto nas novas práticas econômicas, que se beneficiam das inovações informacionais das últimas décadas. Estas abrangem as atividades que se utilizam do patrimônio imaterial, relacionado à produção de bens culturais, inovação tecnológica, produtos culturais por excelência, para ir além do modo de pensar pelo qual a economia tradicional, baseada na extração e manufatura de recursos naturais se limita.

O Esporte em geral está abrangido por esse esquema de pensamento, tanto de forma direta, tal como a própria busca por novos streams de rendimentos pelos clubes, quanto de forma indireta pela valorização da marca, turismo, fomento à cultura e educação para o esporte, artesanato, gastronomia, além de uma série de atividades relacionadas e decorrentes do esporte ou dos megaeventos esportivos.

O conceito de esporte-espetáculo, segundo Rodrigues e Montagner, diz respeito ao desporto praticado com foco no alto rendimento do atleta, e que é reproduzido por diferentes meios de informação, sendo o mais poderoso a mídia eletrônica, representado pelos meios de comunicação de massa - rádio, televisão, internet. ${ }^{1}$

Proni igualmente delimita o conceito de esporte-espetáculo:

\footnotetext{
${ }^{1}$ RODRIGUES, Eduardo Fantato; MONTAGNER, Paulo César. Esporte-espetáculo, televisão e pedagogia do esporte: o que crianças compreendem e as relações com um programa esportivo de televisão. Revista Digital Lecturas: Educación Física y Deportes, Buenos Aires, n. 10, v. 85, 2005.
} 
i. referem-se a competições esportivas organizadas por ligas ou federações, que reúnem atletas submetidos a esquemas intensivos de treinamento (no caso de modalidades coletivas, a disputa envolve equipes formalmente constituídas); ii. tais competições esportivas tornaram-se espetáculos veiculados e reportados pelos meios de comunicação de massa e são apreciadas no tempo de lazer do espectador (ou seja, satisfazem a um público ávido por disputas ou proezas atléticas); e iii. a espetacularização motivou a introdução de relações mercantis no campo esportivo, seja porque conduziu ao assalariamento dos atletas, seja em razão dos eventos esportivos apresentados como entretenimento de massa passarem a ser financiados (pelo menos em parte) através da comercialização do espetáculo. ${ }^{2}$

No futebol, mais do que nos outros esportes, fica clara a caracterização nessa categoria, no Brasil e nos demais países, fenômeno evidenciado até mais recentemente em países asiáticos e nos Estados Unidos.

A ideia de futebol-espetáculo está amplamente relacionada à noção de futebolempresa, uma vez que a atividade empresarial em grande escala, com a profissionalização da gestão nas equipes tem sido responsável pela midiatização, regulamentação e grande exploração comercial desse esporte. 0 futebol europeu e em especial o inglês foi o grande precursor desse modelo, mediante a alta especialização técnica da gestão e exploração comercial dessa atividade $^{3}$. Hoje a experiência internacional dos grandes clubes, espanhóis, italianos, alemães, ingleses, dentre outros, movimentam milhões em recursos e bens intangíveis, congregando pessoas em todo o mundo em torno dos seus espetáculos midiáticos.

No Brasil, não obstante problemas recentes em torno da institucionalização desse esporte - por exemplo, de ordem trabalhista e de transparência fiscal, o fato de o país ter sido sede da última Copa do Mundo de Futebol e permanecer como um celeiro permanente de jovens desportistas talentosos para o mundo todo, a instituição do futebol-empresa vem ainda se firmando como atrativo econômico de grande expressividade.

\subsection{Legislação, regulação e incentivos ao futebol no Brasil}

O futebol profissional foi sendo reestruturado desde os anos setenta, segundo Proni ${ }^{4} \mathrm{e}$ adotada uma lógica mercantil que se sobrepôs à organização esportiva e "se convertendo em veículo de publicidade", com novos determinantes que passaram a influir na sua gestão, uma vez

\footnotetext{
${ }^{2}$ PRONI, Marcelo Weishaupt. Esporte-espetáculo e futebol-empresa. 1998. Tese (Doutorado em Educação Física) - Faculdade de Educação Física, Universidade Estadual de Campinas, Campinas, 1998, p. 85.

${ }^{3}$ Ibidem, p. 85.

${ }^{4}$ Ibidem, p. 85.
} 

PROMOÇ̃̃O CULTURAL PARA O DESENVOLVIMENTO

que organizado como uma atividade comercial complexa, e proporcionado como espetáculo e produto muito valioso para a indústria do entretenimento.

A mais recente mudança institucional com origem no setor público foi a edição da Lei Federal n. 13.155/2015, a Lei de Responsabilidade Fiscal no Esporte - LRFE, que vem a interferir diretamente na gestão dos clubes de futebol, para impor limites e parâmetros aos clubes, regulamentar a atividade no tocante ao incremento da governança, e cujo objetivo direito relaciona-se parcelamento de dívidas e o aumento da transparência na gestão dos clubes, ponto crucial na sua manutenção e cada vez mais forte relação com o mercado:

Art. $1^{\circ}$ Esta Lei de Responsabilidade Fiscal do Esporte - LRFE estabelece princípios e práticas de responsabilidade fiscal e financeira e de gestão transparente e democrática para entidades desportivas profissionais de futebol, cria o Programa de Modernização da Gestão e de Responsabilidade Fiscal do Futebol Brasileiro e dispõe sobre a gestão temerária no âmbito das referidas entidades. ${ }^{5}$

A sustentabilidade de um time depende de sua gestão. 0 desejo de contratar determinado jogador, construir um novo estádio, oferecer uma melhor experiência para o torcedor do time, dependem de uma equipe capacitada de diretores que tenham o know how e as conexões necessárias para efetivá-las. Embora não seja possível afirmar de forma definitiva que há uma relação de causalidade, nota-se de forma clara uma conexão entre tais fatores e o sucesso de um clube. A diretoria de um time não pode mais ser formada por "cartolas" e empresários de jogadores como outrora. Há uma necessidade de profissionalização e modernização da gestão dos times.

Nesse sentido, Leoncini e Silva destacam que a "administração dos dirigentes tradicionais de clubes e federações de futebol tem sido apontada como a causa mor que faz com que o futebol brasileiro não consiga aproveitar plenamente seu potencial econômico, principalmente nos chamados agentes diretos - clubes e federações”。 .

É, nesse contexto, que os maiores clubes do Brasil vêm se modernizando. Um dos exemplos do aperfeiçoamento de gestão é o aumento da transparência em relação às receitas e despesas dos times, sobretudo considerando o inciso I, do art. 46-A, da Lei 9.615, de 24 de

\footnotetext{
${ }^{5}$ BRASIL. Lei № 13.155 , de 4 de agosto de 2015. Estabelece princípios e práticas de responsabilidade fiscal e financeira e de gestão transparente e democrática para entidades desportivas profissionais de futebol. Diário Oficial da União. Brasília: 4 ago. 2015. Disponível em: < http://www.planalto.gov.br/ccivil_03/_ato2015-2018/2015/lei/L13155.htm>. Acesso em: 22 nov. 2016. ${ }^{6}$ LEONCINI, Marvio P.; SILVA, Marcia T. Entendendo o futebol como um negócio: um estudo exploratório. Revista Gestão e Produção, v. 12, n. 1, p. 11-23, 2005, p. 12.
} 

PROMOÇ̃̃O CULTURAL PARA O DESENVOLVIMENTO

março de 1998 (“Lei Pelé”). Os maiores clubes do Brasil como, por exemplo, o Esporte Clube "Bahia"7, o Sport Clube "Internacional"8, "Coritiba" Foot ball Club9 , Sport Club "Corinthians" Paulista $^{10}$, "Fluminense" Football Club ${ }^{11}$ e o Clube de Regatas do "Flamengo"12, dentre outros, disponibilizam "Portais da Transparência" para que os seus torcedores possam verificar as demonstrações financeiras, os resultados financeiros, pareceres dos auditores, atas dos conselhos e assembleias do clube, dentre outros diversos documentos disponíveis, de forma que possam examinar os motivos por trás da falta de recursos para a contratação de determinado jogador ou o atraso dos salários em determinado mês.

Tratativas e negociações que eram feitas nos bastidores, por "trás das cortinas", agora, estão sendo publicizadas, não apenas por exigência legal ou por benevolência dos seus diretores, mas sim por reivindicação dos seus torcedores. O torcedor quer se sentir "parte" de um time, ajudando-o a alcançar a vitórias e tal publicidade é uma das formas daqueles participarem do clube.

Nesse sentido, destaca-se, inclusive, iniciativa pioneira do Coritiba Sport Foot Ball Club, em adotar medidas "Compliance" no modelo de gestão do clube, o que denominaram de "Conduta Coxa Branca". Com tais medidas, possibilita-se o envolvimento dos torcedores e funcionários do time na produção do código de ética e das normas para controle interno, oferecendo canais de denúncia em casos de eventual ocorrência de irregularidade, em prol de práticas de governança da gestão do clube. ${ }^{13}$

Um dos instrumentos elaborados pela LRFE é o Programa de Modernização da Gestão e de Responsabilidade Fiscal do Futebol Brasileiro - Profut ${ }^{14}$, que tem com objetivo de promover a

7 Disponível em: <http://www.esporteclubebahia.com.br/o-clube/transparencia/>. Acesso em: 23 abr. 2016.

${ }^{8}$ SPORT CLUBE INTERNACIONAL. Transparência,2016. Disponível em: <http://transparencia.internacional .com.br>. Acesso em: 23 abr. 2016.

${ }^{9}$ CORITIBA. Transparência, 2016. Disponível em: <http://www.coritiba.com.br/transparencia>. Acesso em: 23 abr. 2016.

${ }^{10}$ CORINTHIANS. Transparência, 2016. Disponível em: <http://www.corinthians.com.br/clube/ transparencia>. Acesso em: 23 abr. 2016.

${ }^{11}$ FLUMINENSE. Transparência, 2016. Disponível em: <http://www.fluminense.com.br/site/futebol/ transparencia>. Acesso em: 23 abr. 2016.

${ }_{12}$ FLAMENGO. Transparência, 2016. Disponível em: <http://www.flamengo.com.br/site/download/ transparencia>. Acesso em: 23 abr. 2016.

${ }^{13}$ MINISTÉRIO DOS ESPORTES. Coritiba lança modelo de gestão compliance e se torna o primeiro clube da América Latina a utilizá-la. Disponível em: <http://www.esporte.gov.br/index.php/ultimasnoticias/209-ultimas-noticias/55132-coritiba-lanca-modelo-de-gestao-compliance-e-se-torna-o-primeiroclube-da-america-latina-a-utiliza-la>. Acesso em: 16 abr. 2016.

${ }^{14}$ BRASIL. Lei $\mathrm{N}^{\circ} 13.155$, de 4 de agosto de 2015. Estabelece princípios e práticas de responsabilidade fiscal e financeira e de gestão transparente e democrática para entidades desportivas profissionais de 

PROMOÇ̃̃O CULTURAL PARA O DESENVOLVIMENTO

gestão transparente e democrática e o equilíbrio financeiro das entidades desportivas profissionais de futebol.

Segundo a Lei 13.155/2015, entende-se como entidade desportiva profissional de futebol a entidade de prática desportiva envolvida em competições de atletas profissionais, nos termos dos arts. 26 e 28 da Lei $n^{\circ}$ 9.615/1998 (que versa sobre normas gerais do desporto), as ligas em que se organizarem e as respectivas entidades de administração de desporto profissional.

A adesão ao PROFUT ocorre com o requerimento das entidades desportivas profissionais de futebol do parcelamento sobre o qual a lei dispõe (art. $3^{\circ}$ ). Dessa afirmação, cabe ressaltar dois pontos. Primeiro, a adesão não é obrigatória para todas as entidades desportivas, sendo exigido um requerimento destas para que as condições legais sejam aplicáveis em seus respectivos casos. Segundo, a adesão ao PROFUT é condição para o parcelamento especial dos débitos dessas entidades perante a União, ou seja, não é possível que esse evento ocorra, sem que os entes adotem as obrigações legais do PROFUT. A partir do momento que a entidade não cumpre as exigências do referido programa, a possibilidade do parcelamento encontra seu fim.

0 prazo final para adesão ao PROFUT, de início, tinha como termo o dia 30 de novembro de 2015. Recentemente, no entanto, houve a edição da Medida Provisória 695/15 reabrindo o citado prazo, até 31 de julho de 2006. No total, em relação a data anterior, segundo a Receita Federal houve a adesão de 111 clubes de futebol, os quais, juntos, possuem dívidas de $\mathrm{R} \$ 3,83$ bilhões, com o Fisco e a Procuradoria-Geral da Fazenda Nacional ${ }^{15}$. Todos os clubes da Série A, exceto três times, aderiram ao PROFUT ${ }^{16}$, o que demonstra a preocupação dos clubes-empresas com a regularização de suas contas, mesmo que sejam necessárias contrapartidas.

Do ponto de vista do incremento da governança pública, a ideia da construção de um Pacto Setorial pelo esporte no Brasil - adiante detalhado - surgiu após a aprovação, em 2013, do Artigo 18-A que modificou a Lei Federal n. 9615/1998, a Lei Pelé, que condiciona o repasse de verbas da administração pública direta e indireta, incluindo a Lei de Incentivo ao Esporte - LIE, a uma série de regras, entre elas limite de mandato de dirigentes, participação de atletas na

futebol. Diário Oficial da União. Brasília: 4 ago. 2015. Disponível em: < http://www.planalto.gov.br/ccivil_03/_ato2015-2018/2015/lei/L13155.htm>. Acesso em: 22 nov. 2016.

${ }_{15}$ MÁXIMO, Wellton. Parcelamento de dívidas com União tem adesão de 111 clubes de futebol. Disponível em: <http://www.ebc.com.br/noticias/economia/2015/12/parcelamento-de-dividas-comuniao-tem-adesao-de-111-clubes-de-futebol>. Acesso em: 16 abr. 2016.

16 TERRA. Da Série A, só três clubes não aderem ao Profut. Ao todo, mais de 100 entram no refinanciamento. Disponível em: <http://verdaoweb.terra.com.br/news.asp?nID=26694>. Acesso em: 16 abr. 2016 

PROMOÇ̃̃O CULTURAL PARA O DESENVOLVIMENTO

eleição para cargos de direção, transparência de documentos e contas na gestão. A modificação desse artigo tem suscitado, como exemplifica iniciativas como o Pacto, o interesse nas empresas de contribuírem para a melhoria do esporte no país. Além disso, a Lei Anticorrupção - também conhecida como Lei da Empresa Limpa - em vigor desde janeiro de 2014, trouxe a necessidade de revisão das regras de compliance para os patrocínios.

$\mathrm{Na}$ Lei Pelé, o artigo 18-A estabelece alguns regramentos que merecem ser destacados, haja vista o potencial de impacto na atividade de gestão dos clubes, a saber: (i) seu presidente ou dirigente máximo deverá ter mandato de até 4 (quatro) anos, permitida 1 (uma) única recondução; (ii) destinação integral dos resultados financeiros à manutenção e ao desenvolvimento dos objetivos sociais dos clubes; (iii). Transparência na gestão, inclusive quanto aos dados econômicos e financeiros, contratos, patrocinadores, direitos de imagem, propriedade intelectual e quaisquer outros aspectos de gestão; (iv) Garantia da representação da categoria de atletas no âmbito dos órgãos e conselhos técnicos incumbidos da aprovação de regulamentos das competições; $(v)$ Garantia da existência e a autonomia do seu conselho fiscal.

E ainda, que estabeleçam em seus estatutos: (a) princípios definidores de gestão democrática; (b) instrumentos de controle social; (c) transparência da gestão da movimentação de recursos; (d) fiscalização interna; $(e)$ alternância no exercício dos cargos de direção; $(f)$ aprovação das prestações de contas anuais por conselho de direção, precedida por parecer do conselho fiscal; $(g)$ participação de atletas nos colegiados de direção e na eleição para os cargos da entidade garantam a todos os associados e filiados acesso irrestrito aos documentos e informações relativos à prestação de contas, bem como àqueles relacionados à gestão da respectiva entidade de administração do desporto, os quais deverão ser publicados na íntegra no sítio eletrônico desta ${ }^{17}$.

No intuito de otimizar as relações de governança do esporte no Brasil, foi firmado um acordo entre as empresas patrocinadoras do esporte brasileiro cujo objetivo é melhorar a comunicação e transparência, bem como profissionalizar a gestão desse segmento econômico.

Foi firmado o "Pacto pelo Esporte"18, que sugere aos seus aderentes a adoção de medidas de incremento da transparência, ao assumir o compromisso de publicar permanentemente na internet, ainda como reflexo da recente alteração da Lei Pelé: (a)

17 O Clube de Regatas Flamengo, à exemplo de outros times do Rio de Janeiro, tem sido um dos precursores dos ajustes de governança, como pode ser depreendido da visita no seu sítio eletrônico, com ampla descrição dos processos de transparência. Clube de Regatas do flamengo. Transparência. Acesso em: <http://www.flamengo.com.br/site/download/transparencia>. Acesso em: 07 abr. 2016.

${ }^{18}$ PACTO PELO ESPORTE. Disponível em: <http://pactopeloesporte.org.br/>. Acesso em: 2 abr. 2016 
estatuto da entidade; (b) organograma; (c) atas dos conselhos fiscal (quando houver) e administrativo; $(d)$ dados das demonstrações financeiras anuais; $(e)$ código de ética/conduta; $(f)$ política de compras; $(g)$ política de gestão orçamentária/financeira. Sugere ainda aos aderentes estabelecer Conselho Consultivo ou órgão similar independente da administração: (a) participação de especialistas de diversas áreas; $(b)$ envolvimento de atletas. Estabelecer Plano de metas para os clubes, objetivando o desenvolvimento do Futebol, dentre outras mediadas similares.

São mudanças importantes para a profissionalização da gestão dos clubes e certamente trarão impactos em curto prazo para os aderentes e para a sociedade como um todo, que tem investido valores significativos nos programas privados de incentivo aos clubes - como os programas de sócio torcedor, dentre outros similares, bem como favorecido aspectos de incentivo, com base em destinações fiscais provenientes do financiamento público.

\subsection{A governança corporativa como fator de promoção da atividade futebolística}

A melhoria da governança corporativa no futebol nacional vem surgindo como tendência da profissionalização da gestão dessa atividade, a partir da adoção processos de acompanhamento internos e de novas estratégias de gestão empresarial. A governança corporativa, portanto, é entendida em linhas gerais, como um sistema pelo qual as empresas são geridas e incentivadas, envolvendo os relacionamentos entre sócios, conselhos de administração, diretorias, órgãos de fiscalização e controle e demais partes interessadas. ${ }^{19}$

No tocante aos processos de captação de recursos as principais fontes de receitas dos clubes sempre foram: (i) publicidade nos uniformes do clube e exploração da marca nas vendas de equipamentos esportivos, em geral; (ii) direitos de transmissão; (iii) ingressos das partidas. Entretanto, dado o volume bilionário de recursos financeiros movimentado pelo futebol, este tem sido visto cada vez mais como expressão econômica significativa no meio empresarial nas áreas de comunicação e entretenimento, com os desdobramentos na geração de marcas e royalties diversos, típicos da economia criativa, baseada no intangível.

A título de exemplo, podem-se citar alguns indicadores que demonstram os valores significativos que o esporte movimenta. De acordo com a empresa de consultoria empresarial

${ }^{19}$ IBGC. Governança corporativa. Disponível em: <http://www.ibgc.org.br/inter.php?id=18161>. Acesso em: 03 abr. 2016. 

PROMOCÃO CULTURAL PARA O DESENVOLVIMENTO

A.T. Kearney, em 2014, o mercado de eventos esportivos poderia ser valorizado em mais de 80 bilhões de dólares ${ }^{20}$. Os canais de televisão SkySports e BT Sports pagaram 5,50 bilhões de euros para reter os poderes de transmissão domésticos dos jogos da Premier League, campeonato de futebol inglês, por três temporadas e estima-se que a liga receberá mais de 3 bilhões de euros na venda dos direitos de transmissão internacionais ${ }^{21}$. No Brasil, por sua vez, segundo a TV Globo, em 2015, foi destinado R\$ 1,1 bilhão para o pagamento dos direitos de transmissão do Brasileirão, valor que foi dividido entre 23 clubes, sendo 20 da Série A, e Botafogo, Bahia e Vitória, que caíram para Série B. ${ }^{22}$

No cenário brasileiro, a realidade econômica relacionada aos problemas de má gestão dos clubes não tem evidenciado um cenário que acompanhe a tendência mundial. Receitas tendem a decrescer - não obstante a crise econômica que o país tem sofrido -, mas como tendência até mesmo motivada pelo mau desempenho dos clubes nos campeonatos nacionais.

As perdas de arrecadação com ingressos acontecem, uma vez que o número de pessoas que vão aos estádios diminui. ${ }^{23}$ Os clubes também encontram dificuldade na busca de publicidade, sobretudo patrocinadores master $^{24}$, ou seja, de maior destaque no uniforme dos times, de forma que os clubes precisam encontrar alternativas, como patrocínios temporários como ocorreu com o Santos Futebol Clube ${ }^{25}$ - e patrocínios apresentando ofertas em promoção como ocorreu no caso do Botafogo ${ }^{26}$, para obterem receitas.

20 ATKEARNEY. Winning the Business of Sports. Disponível em: <https://www.atkearney.com/documents/10192/5258876/Winning+in+the+Business+of+Sports.pdf/ed85b 644-7633-469d-8f7a-99e4a50aadc8>. Acesso em: 16 abr. 2016.

21 TOTALSPPORTEK. Premier League TV Rights Money Distribution (2016-19). Disponível em: <http://www.totalsportek.com/money/premier-league-tv-rights-money-distribution/>. Acesso em: 16 abr. 2016.

${ }^{22}$ COBRA, Caique. Brasileirão: Saiba quanto seu clube ganha de dinheiro da TV Globo. Disponível em: <http://torcedores.com/noticias/2015/09/brasileirao-saiba-quanto-seu-clube-ganha-de-dinheiro-da-tvglobo>. Acesso em: 16 abr. 2016.

${ }^{23}$ FRANCO JÚNIOR Júnior, H. Brasil, país do futebol?. Revista USP, v. 99, pp. 45-56, 2013.

${ }^{24} \mathrm{O}$ Santos Futebol Clube, por exemplo, passou mais de dois anos sem patrocínio master, negociando, de maneira temporário, a referida publicidade nos jogos "clássicos". Cf. A TRIBUNA. Sem master há mais de dois anos, Santos negocia com rede de sorvetes. Disponível em: <http://www.atribuna.com.br/noticias/noticias-detalhe/esportes/sem-master-ha-mais-de-dois-anossantos-negocia-com-rede-de-sorvetes/?cHash=73b7e78a8406dd02946f0b056836915f >. Acesso em: 14. nov. 2015.

${ }^{25}$ GLOBOESPORTE.COM. Santos fecha patrocínio master para clássico contra o Palmeiras, na Vila. Disponível em: <http://globoesporte.globo.com/futebol/times/santos/noticia/2015/10/santos-fechapatrocinio-master-para-classico-contra-o-palmeiras-na-vila.html>. Acesso em: 14 nov. 2015.

26 UOLESPORTE. Patrocinador do Botafogo faz 'promoção' e muda preço de anúncio na camisa. Disponível em: <http://uolesporte.blogosfera.uol.com.br/2015/03/08/patrocinador-do-botafogo-fazpromocao-e-muda-preco-de-anuncio-na-camisa/>. Acesso em: 14 nov. 2015. 
Os direitos de transmissão, por sua vez, são influenciados por essas duas outras receitas. As emissoras de televisão sabem que os clubes precisam de recursos, alguns para, pelo menos, deixar os salários e os direitos de imagem dos jogadores em dia, e iniciam as negociações quanto aos valores de direito de receita em posição de vantagem ${ }^{27}$. Não apenas nos clubes menores, como também os grandes clubes nacionais.

É nesse aspecto que os clubes têm se beneficiado cada vez mais da indústria do entretenimento e de suas tendências mundiais, características do ambiente da economia criativa, tanto em busca de forma alternativas de obtenção de receita, baseada em bens e ativos intangíveis com farta exploração da marca, sejam enquanto agentes de promoção cultural do esporte.

Um dos principais modos de ativação desse patrimônio intangível, que vem ganhando monta, é a ideia do sócio torcedor, separado por níveis, cada um com mais vantagens do que o anterior, por meio de pagamentos mensais ou anuais dos seus torcedores. A título de exemplo, o Sport Club Internacional, que é o time com maior número de sócio-torcedores, possui mais de 147 mil torcedores que acolheram essa ideia. O referido clube oferece quatro modalidades para o torcedor: (i) Sócio Coloradinho, por R\$ 5,00, mensal (o torcedor participa de promoção e sorteios do clube, descontos na rede credenciada e a revista coloradinho); (ii) Sócio nada vai nos separar, por R\$20,00, mensal (o torcedor possui preferência na compra do ingresso, participa de promoção e sorteios do clube, descontos na rede credenciada, isenção ou desconto no museu, visita colorida ou estacionamento do Beira-Rio - estádio do clube, direito a voto e concorrer nas eleições do clube, revista digital e descontos no parque gigante); (iii) Sócio Campeão do Mundo, por R\$ 40,00, mensal (o torcedor terá as mesmas vantagens da modalidade anterior, mas também terá direito a revista impressa do clube e ingresso com no mínimo 50\% de desconto); e, por fim, (iv) Sócio Cadeira Locada, por R\$ 155,00, mensal (além das vantagens da modalidade anterior, o sócio-torcedor terá acesso garantido aos jogos que sejam realizados no Beira-Rio). ${ }^{28}$

O Sport Club Corinthians Paulista, com mais de 136 mil sócio-torcedores, também oferece modalidades semelhantes, dividindo em cinco modos diferentes, que podem ser pagos

${ }^{27}$ GONÇALVES, Emerson. Evolução das receitas dos direitos de transmissão e como ela é composta no Flamengo. Disponível em: <http://globoesporte.globo.com/blogs/especial-blog/olhar-cronicoesportivo/post/evolucao-das-receitas-dos-direitos-de-transmissao.html>. Acesso em: 14 nov. 2015.

28 INTERNACIONAL. Modalidades de associação. Disponível em: <http://www. internacional.com.br/conteudo?modulo=8\&setor=158\&codigo=\&r=1>. Acesso em: 14 nov. 2015. 
mensal ou anualmente, denominado de Programa Fiel Torcedor $^{29}$. A Sociedade Esportiva Palmeiras, com mais de 126 mil sócio-torcedores, oferece três modalidades, com vantagens particulares para cada nível. ${ }^{30}$

Cada vez mais os clubes estão buscando fidelizar os seus torcedores, de forma que estes não se limitem a assistir apenas um ou dois jogos por ano e comprar uma camisa do time, indo além, oferecendo vantagens para que esses participem continuamente do clube e, com isso, paguem determinada quantia para usufruir dessas vantagens, conforme pode ser constatado no Torcedômetro $^{31}$, que expõe o ranking dos clubes com o maior número de sócio-torcedores. Os clubes, desse modo, querem que os torcedores "participem" da vida do time, de forma contínua, e não apenas nos clássicos, tanto é que o Internacional permite o direito a voto e concorrer nas eleições do clube ${ }^{32}$. Para a garantia do sucesso dessas captações e transações, a melhoria da governança pública e empresarial do futebol é um passo fundamental.

Outro novo modo de ativação financeira que pode ser observado é o incentivo de apostas no Timemania, loteria criada para que os clubes de futebol profissional paguem suas dívidas públicas, acessando, a Certidão Negativa de Débito de Tributos e Contribuições Federais (CND), qualificando-os para a obtenção de incentivos fiscais e patrocínios públicos. Uma das principais vantagens para os clubes é que, enquanto o governo federal permanece com $67 \%$ da arrecadação da Mega-Sena, no caso da Timemania, parcela desse percentual é direcionada aos clubes participantes. Assim, o torcedor ao apostar no Timemania no seu clube preferido, ajuda o seu time.

Merece destaque os casos de crowdfunding, seja entre os próprios torcedores, seja entre os torcedores e os clubes de futebol. O crowdfunding é uma forma de financiamento coletivo que permite a obtenção de capital para iniciativas de interesse coletivo, no caso dos clubes, por meio de diversas fontes de financiamento, tal como seus próprios torcedores.

Há casos de times que fizeram crowdfunding para pagamento de dívidas (como o

${ }^{29}$ FIEL TORCEDOR. Planos. Disponível: <http://www.fieltorcedor.com.br/planos.asp>. Acesso em: 14 nov. 2015.

30 SÓCIO PALMEIRAS. Associa-se. Disponível em: <https://socio-palmeiras.futebolcard.com>. Acesso em: 14 nov. 2015.

31 HISTORICO FUTEBOL MELHOR. Torcedômetro. Disponível em: <http:/ / historicofutebolmelhor.com.br/torcedometro>. Acesso em: 14 nov. 2015.

32 INTERNACIONAL. Modalidades de associação. Disponível em: <http://www.internacional.com.br/conteudo?modulo=8\&setor=158\&codigo=\&r=1>. Acesso em: 14 nov. 2015. 
projeto Vasco Dívida Zero ${ }^{33}$, que arrecadou mais de R\$ 1 milhão para o clube), para contratação de jogadores por meio da plataforma MOP - My Own Player, como no caso do Palmeiras para a contratação do volante Wesley ${ }^{34}$, e, até mesmo, para construção de um estádio próprio para o clube como está ocorrendo com o América Futebol Clube do Rio Grande do Norte, que solicita aos seus torcedores a doação de sacos de cimento, criando até mesmo o "cimentômetro" 35 .

Ressalta-se, no entanto, que o uso do crowdfunding no futebol vem sendo criticado, porque são poucas as vantagens para os torcedores que participam, isto é, em sua maioria, não há contrapartida. Em regra, o crowdfunding é utilizado em projetos que os seus financiadores observam um protótipo ou uma ideia inicial e pagam antecipadamente para que o empreendedor possua capital suficiente para trazer a ideia ao mercado, como ocorre no caso do Kickstarter. No caso do futebol, mais especificamente, a contrapartida em relação ao financiamento para contratação de um jogador é quase nula.

Em suma, esses três modos de obtenção de receita são exemplos de modos que os clubes buscam, aumentar suas receitas e manter o mínimo de sustentabilidade do clube. Embora sejam iniciativas merecedores de destaque, cabe ressaltar que apenas a primeira possui um objetivo de longo prazo, buscando manter uma constância de recursos na receita no clube. Destaca-se que os clubes estão se modernizando, comportando-se como verdadeiras empresas. E, como a maioria das empresas, há necessidade de investidores para a direção e governança do empreendimento. Investidores, por sua vez, em via de regra, evitam injetar recursos em empresas que necessitam de recursos constantemente. Os clubes-empresa, sobretudo no Brasil, precisam de injeções constantes, por vezes, até para manter os salários dos jogadores em dia.

Berton, Bazanini e Donaire ressaltam o papel simbólico do futebol e a sua projeção nos anos recentes: "Nas últimas décadas, o mercado de bens simbólicos do futebol cada vez mais se transformou em negócio bilionário e complexo, acentuadamente, em decorrência de fatores tanto exógenos quanto endógenos". Dentre os fatores externos ou institucionais, ressaltam o papel da Lei Pelé, marco através do qual o "empresário de futebol passou a atuar em nível internacional, junto aos grupos econômicos das mais diversas origens, investindo os lucros

\footnotetext{
${ }^{33}$ VASCO. Vasco Dívida Zero. Disponível em: <http://www.vascodividazero.com.br>. Acesso em: 14 nov. 2015.

34 ADNEWS. Palmeiras recorre a crowdfunding para contratar jogador. Disponível em: <http://www.adnews.com.br/negocios/palmeiras-recorre-a-crowdfunding-para-contratar-jogador>. Acesso em: 14 nov. 2015.

35 VERMELHO DE PAIXÃO. Mais 100 sacos de cimento para arena. Disponível em: <http://www.vermelhodepaixao.com.br/2015/02/mais-100-sacos-de-cimento-para-arena.htm>. Acesso em: 14 nov. 2015.
} 

PROMOÇ̃̃O CULTURAL PARA O DESENVOLVIMENTO

obtidos nas transações nos mais diferentes mercados financeiros do mundo". Por consequência, fatores endógenos ligados ao tratamento das marcas, identidade e personalidade foram evidenciados, como estratégias de marketing. ${ }^{36}$

Desse modo, vem sendo observada uma mudança de paradigma paulatina no Brasil, em prol da governança e planejamento da atividade. Certamente essa iniciativa só vem a reforçar o alcance do futebol como patrimônio cultural dos brasileiros.

\section{FUTEBOL E DESENVOLVIMENTO NO CONTEXTO DA ECONOMIA CRIATIVA}

Para melhor contextualizar a atividade do futebol-espetáculo no ambiente da economia criativa, faz-se necessário estabelecer as premissas pelas quais se pode caracterizar o modelo de desenvolvimento que se pretende tomar como categoria de análise. Sem dúvida, a contemporaneidade impõe que os pilares do desenvolvimento sustentável abordados por Leff: econômico, social, ecológico, cultural e espacial, representam parâmetros relevantes para esse estudo $^{37}$.

No tocante à abordagem econômica, Leff afirma que "a convulsão dos fundamentos que sustentam hoje a ordem econômica dominante nos coloca diante do desafio de transformar, a partir de suas bases, o paradigma insustentável da economia” ${ }^{38}$ e critica a forma como o consumo tem direcionado a economia, por meio da busca incessante pela acumulação do capital privado $^{39}$. Na atividade desportiva, no entanto, o futebol como esporte de massas e forte apelo popular no campo cultural, pode representar uma possibilidade de inclusão social e disseminação de valores éticos importantes. A midiatização do futebol, nesse sentido, tem aspectos bastante positivos.

Nesse sentido, os aspectos social e ecológico também adquirem relevo, haja vista as

\footnotetext{
36 BERTON, R., BAZANINI, R., DONAIRE, D. Mercado de Bens Simbólicos do Futebol: A Estratégia Empreendedora da Gestão Andrés Sanchez no Sport Club Corinthians Paulista. Podium Sport, Leisure and Tourism Review, 2, jun. 2013. Disponível em: <http://www.podiumreview.org.br/ojs/index.php/ rgesporte/article/view/35>. Acesso em: 08 abr. 2016.

37 LEFF, Enrique. Saber ambiental: sustentabilidade, racionalidade, complexidade, poder. 6. ed. Petrópolis: Vozes, 2008.

38 LEFF, Enrique. Saber ambiental: sustentabilidade, racionalidade, complexidade, poder. 6. ed. Petrópolis: Vozes, 2008. p. 42-43. Nesse contexto, recomenda-se a leitura: QUERINO, Ana Célia; SILVA, Juvêncio Borges. Diversidade cultural: proteção e tutela na pós-modernidade. Revista Direito e Liberdade, Natal, v. 16, n. 3, p. 11-35, set./dez. 2014. Quadrimestral.

${ }^{39}$ Nesse sentido, ver PORTO, Antonio Augusto Cruz; TORRES, Cibele Merlin. A importância da percepção holística do consumidor como suporte de uma sociedade perdurável. Revista Direito e Liberdade, Natal, v. 15, n. 2, p. 63-92, maio/ago. 2013. Quadrimestral.
} 
inúmeras possibilidades de geração de bens e insumos decorrentes dessa atividade econômica, inteiramente baseada em bens intangíveis, típica dos empreendimentos econômicos criativos.

A mesma lógica do intangível, que faz com que o futebol seja capaz de atrair seguidores em qualquer lugar do planeta, relativizando o espaço e tratando dos seus empreendimentos como de contexto global, sem limites ou fronteiras espaciais, globaliza a atividade no seu sentido mais positivo de influência. Outra métrica útil no campo espacial é a do desenvolvimento local proporcionado pela atividade.

O pilar cultural denota um grande potencial de análise, haja vista o impacto dessa atividade no mundo líquido global ${ }^{40}$, no qual as relações geradas em torno do futebol impactam pela produção e distribuição de bens culturais, conectando pessoas no mundo todo, há mais de um século:

O futebol é uma empresa criativa que conecta pessoas através de fronteiras políticas, geográficas e temporais. É criativo, tanto por causa do "produto" os jogadores produzem no campo, mas também por causa dos "produtos" que os fãs adquirem, blogs e memes culturais (hinos, canções, fã-clubes, postagens em internet, etc.). O Futebol contribui para a humanidade, pois permite que as pessoas a criem novas ideias e instituições culturais. Futebol, em seguida, faz parte da economia criativa, porque enfatiza a nossa humanidade (tradução nossa). ${ }^{41}$

Acerca dos aspectos geopolíticos do futebol, seu alcance rompe fronteiras e barreiras sociais e econômicas, através da inclusão proporcionada pelo seu caráter midiático.

Em Bauman, foi cunhado o termo "modernidade líquida”, momento histórico atual no qual a figura do "consumidor", ou seja, aquele que se coloca diante de um produto para consumo, torna-se um ser ávido, o que em se tratando do esporte, dada a sua função de promoção de valores humanos benéficos significativos, teria uma função positiva socialmente. Para o mesmo autor a cultura teria tido a função histórica de demarcar as classes sociais, de modo que o tipo de bens culturais consumidos “educam" e definem a posição social das pessoas. $\mathrm{Na}$ “modernidade líquida”, a cultura consiste em ofertas para uma sociedade de consumo,

\footnotetext{
${ }^{40}$ BAUMAN, Zygmunt. A cultura no mundo líquido moderno. Rio de Janeiro: Zahar Editores, 2013. 111p.

41 "Soccer is a creative enterprise that connects people across political, geographic, and temporal boundaries. It is creative both because of the "product" the players produce on the field, but also because of the "products" the fans make, such as fan tributes, blogs, and cultural memes (chants, songs, fan clubs, etc.). Soccer contributes to humanity because it allows people to create new ideas and cultural institutions. Soccer then is part of the creative economy, because it emphasizes our humanity." (GALLARD, Grant. Why Football is Part of the Creative Economy. Soccer politics. Disponível em: <https://sites.duke.edu/wcwp/2012/09/01/why-football-is-part-of-the-creative-economy/>. Acesso em: 02 abr. 2016.
} 
orientada pela flexibilidade de padrões e em constante mudança: a cultura de hoje não está direcionada para afirmar interesses de classe, mas sim para garantir o consumismo em níveis globais. Como esporte massivo, espetacularizado, o futebol vence as barreiras sociais e inclui pessoas em torno do seu ideal de bem cultural cada vez mais liquefeito, no melhor sentido dessa expressão, ao atingir a todos indiscriminadamente, de todas as classes sociais. ${ }^{42}$

Uma vez revisitadas as dimensões do desenvolvimento sustentável tais como ressaltadas em Leff, são vários os argumentos em prol do futebol como agente de desenvolvimento sustentável no campo da Economia Criativa na contemporaneidade, com ganhos econômicos, sociais, ecológicos, sociais, culturais e espaciais. ${ }^{43}$

\section{CONCLUSÃO}

Por todo exposto, confirmou-se a hipótese da pesquisa de que o futebol contribui para a economia criativa e esta, inclusive, é fundamental para a sustentabilidade dos clubes de futebol. É que investidores estrangeiros, donos milionários e/ou bilionários, que possuíam times de futebol como hobby estão se tornando cada vez mais raros, de forma que os clubes precisam de outras fontes de renda para manter as suas equipes competitivas, ao mesmo tempo, que também devem adimplir as obrigações assumidas em dia.

A título exemplificativo, com objetivo de demonstrar a interface entre o futebol e a economia criativa, citou-se novas iniciativas dos clubes, tal como a criação de sócio-torcedores e o uso de crowdfunding para pagamento de dívidas e para contratação de jogadores. Trata-se de modos alternativos que se tornaram possíveis a partir da economia criativa e que, em um contexto de economia dogmática, não seriam possíveis. Nesse contexto, além de ajudar financeiramente o time, a economia criativa também possibilita a participação do torcedor na gestão do time e na própria governança do clube que está auxiliando.

O futebol é ao mesmo tempo um símbolo cultural e uma atividade econômica de alta rentabilidade, de modo que sua institucionalização nos campos privado e público tem sido ampliada com o incremento de leis de proteção da governança e relacionamento entre entes diversos, com o objetivo de fomentar o desporto, mas com o diferencial da responsabilização fiscal, social e corporativa.

\footnotetext{
42 BAUMAN, Zygmunt. A cultura no mundo líquido moderno. Rio de Janeiro: Zahar Editores, 2013. 111p. 43 LEFF, Enrique. Saber ambiental: sustentabilidade, racionalidade, complexidade, poder. 6. ed. Petrópolis: Vozes, 2008.
} 
Trata-se de atividade que agrega elevadas somas e interações de atores, bem como devido a sua natureza de patrimônio imaterial e cultural, o futebol enquadra-se perfeitamente nesse cenário de promoção da economia criativa, e ainda mais valorizado pela sua capacidade de projetar-se entre as atividades sustentáveis, com benefícios não só econômicos, mas também sociais, espaciais, ecológicos e sobretudo culturais.

\section{REFERÊNCIAS}

A TRIBUNA. Sem master há mais de dois anos, Santos negocia com rede de sorvetes. Disponível em: <http://www.atribuna.com.br/noticias/noticias-detalhe/esportes/sem-masterha-mais-de-dois-anos-santos-negocia-com-rede-de-sorvetes/?cHash=73b7e78a8406dd02946 f0b056836915f>. Acesso em: 14. nov. 2015.

ADNEWS. Palmeiras recorre a crowdfunding para contratar jogador. Disponível em: <http://www.adnews.com.br/negocios/palmeiras-recorre-a-crowdfunding-para-contratarjogador>. Acesso em: 14 nov. 2015.

ALVES, José Antônio Barros; PIERANTI, Octavio Penna. O estado e a formulação de uma política nacional de esporte no Brasil. RAE electron., São PaulO, v. 6, n. 1, jul. 2007. Disponível em: <http://www.scielo.br/scielo.php?script=sci_arttext\&pid=S1676-56482007000100002\&lng =en\&nrm=iso>. Acesso em: 02 abr. 2016.

ALVITO, M. A parte que te cabe nesse latifúndio: o futebol brasileiro e a globalização. Análise Social, Lisboa, v. 41, n.179, p.451-474, 2006

ATKEARNEY. Winning the Business of Sports. Disponível em: <https://www.atkearney.com/documents/10192/5258876/Winning+in+the+Business+of+Sports.p df/ed85b644-7633-469d-8f7a-99e4a50aadc8>. Acesso em: 16 abr. 2016.

BAUMAN, Zygmunt. A cultura no mundo líquido moderno. Rio de Janeiro: Zahar Editores, 2013. $111 \mathrm{p}$.

BENTO, Jorge Olímpio. Futebol: sonhos, paixões e cultura. Revista USP 99, v. 11, n. 30, 2013.

BERTON, R., BAZANINI, R., DONAIRE, D. Mercado de Bens Simbólicos do Futebol: A Estratégia Empreendedora da Gestão Andrés Sanchez no Sport Club Corinthians Paulista. Podium Sport, Leisure and Tourism Review, v. 2, jun. 2013. Disponível em:

<http://www.podiumreview.org.br/ojs/index.php/rgesporte/article/view/35>. Acesso em: 08 abr. 2016.

BRASIL. Lei № 13.155, de 4 de agosto de 2015. Estabelece princípios e práticas de responsabilidade fiscal e financeira e de gestão transparente e democrática para entidades desportivas profissionais de futebol. Diário Oficial da União. Brasília: 4 ago. 2015. Disponível 

PROMOÇ̃̃O CULTURAL PARA O DESENVOLVIMENTO

em: < http://www.planalto.gov.br/ccivil_03/_ato2015-2018/2015/lei/L13155.htm>. Acesso em: 22 nov. 2016.

. Ministério da Cultura. Plano da Secretaria da Economia Criativa: políticas, diretrizes e ações, 2011-2014. Brasília, 2011.

. RECEITA FEDERAL. Legislação. PROFUT. Acesso em:

http://idg.receita.fazenda.gov.br/acesso-rapido/legislacao/legislacao-porassunto/parcelamento-da-mp-no-671-2015-times-de-futebol-profut. Acesso em: 2 abr. 2016.

CLUBE DE REGATAS DO FLAMENGO. Transparência. Acesso em:

http://www.flamengo.com.br/site/download/transparencia. Acesso em: 07 abr. 2016.

COBRA, Caique. Brasileirão: Saiba quanto seu clube ganha de dinheiro da TV Globo. Disponível em: <http://torcedores.com/noticias/2015/09/brasileirao-saiba-quanto-seu-clube-ganha-dedinheiro-da-tv-globo>. Acesso em: 16 abr. 2016.

DAMO, A. S.; OLIVEN, R. G. O Brasil no horizonte dos megaeventos esportivos de 2014 e 2016: sua cara, seus sócios e seus negócios. Horizontes antropológicos, Porto Alegre, ano 19, n. 40, p. 19-63, jul./dez. 2013

FERKINS, Lesley; SHILBURY, David; MCDONALD, Gael. The role of the board in building strategic capability: Towards an integrated model of sport governance research. Sport Management Review, v. 8, n. 3, p. 195-225, 2005.

FIEL TORCEDOR. Planos. Disponível: <http://www.fieltorcedor.com.br/planos.asp>. Acesso em: 14 nov. 2015.

FRANCO JÚNIOR Júnior, H. Brasil, país do futebol?. Revista USP, v. 99, pp. 45-56, 2013.

GALLARD, Grant. Why Football is Part of the Creative Economy. Soccer politics. Disponível em: <https: / / sites.duke.edu/wcwp/2012/09/01/why-football-is-part-of-the-creative-economy/>. Acesso em: 02 abr. 2016.

HISTORICO FUTEBOL MELHOR. Torcedômetro. Disponível em:

<http://historicofutebolmelhor.com.br/torcedometro>. Acesso em: 14 nov. 2015.

HUGHES, Rob. Former Star on the Soccer Field Tries to Level It. The saturday profile. The New York Times, 31 de out. 2009. Disponível em:

<http://www.nytimes.com/2009/10/31/world/europe/31platini.html?_r=1>. Acesso em: 22 ago. 2015

GLOBOESPORTE.COM. Conselho Fiscal reprova contas do Vasco pelo quarto ano consecutive. Disponível em:

<http://globoesporte.globo.com/futebol/times/vasco/noticia/2013/12/conselho-fiscal-reprovacontas-do-vasco-pelo-quarto-ano-consecutivo.html>. Acesso em: 20 set. 2015.

. Santos fecha patrocínio master para clássico contra o Palmeiras, na Vila. Disponível em: <http://globoesporte.globo.com/futebol/times/santos/noticia/2015/10/santos-fecha- 

PROMOÇ̃̃O CULTURAL PARA O DESENVOLVIMENTO

patrocinio-master-para-classico-contra-o-palmeiras-na-vila.html>. Acesso em: 14 nov. 2015.

GONÇALVES, Emerson. Evolução das receitas dos direitos de transmissão e como ela é composta no Flamengo. Disponível em: <http://globoesporte.globo.com/blogs/especialblog/olhar-cronico-esportivo/post/evolucao-das-receitas-dos-direitos-de-transmissao.html>. Acesso em: 14 nov. 2015.

IBGC. Governança corporativa. Disponível em:<http://www.ibgc.org.br/inter.php?id=18161>. Acesso em: 03 abr. 2016.

INTERNACIONAL. Modalidades de associação. Disponível em: <http: / / www. internacional.com.br/conteudo?modulo=8\&setor=158\&codigo=\&r=1 >. Acesso em: 14 nov. 2015.

JARVIE, Grant. Sport, culture and society: an introduction. Routledge, 2013.

LEFF, Enrique. Saber ambiental: sustentabilidade, racionalidade, complexidade, poder. 6. ed. Petrópolis: Vozes, 2008.

LEONCINI, Marvio P.; SILVA, Marcia T. Entendendo o futebol como um negócio: um estudo exploratório. Revista Gestão e Produção, v. 12, n. 1, p. 11-23, 2005.

MÁXIMO, Wellton. Parcelamento de dívidas com União tem adesão de 111 clubes de futebol. Disponível em: <http://www.ebc.com.br/noticias/economia/2015/12/parcelamento-de-dividascom-uniao-tem-adesao-de-111-clubes-de-futebol>. Acesso em: 16 abr. 2016.

MINISTÉRIO DOS ESPORTES. Coritiba lança modelo de gestão compliance e se torna o primeiro clube da América Latina a utilizá-la. Disponível em:

<http://www.esporte.gov.br/index.php/ultimas-noticias/209-ultimas-noticias/55132-coritibalanca-modelo-de-gestao-compliance-e-se-torna-o-primeiro-clube-da-america-latina-a-utiliza-la>. Acesso em: 16 abr. 2016.

PACTO PELO ESPORTE. Disponível em: http://pactopeloesporte.org.br/. Acesso em: 2 abr. 2016

PERRUCI, Felipe Falcone. Clube-empresa: o modelo brasileiro para transformação dos clubes de futebol em sociedades empresárias. Dissertação (Mestrado em Direito) - Curso de Mestrado da Faculdade de Direito Milton Campos, Faculdade de Direito Milton Campos, Nova Lima, 2006.

PORTO, Antonio Augusto Cruz; TORRES, Cibele Merlin. A importância da percepção holística do consumidor como suporte de uma sociedade perdurável. Revista Direito e Liberdade, Natal, v. 15, n. 2, p. 63-92, maio/ago. 2013. Quadrimestral.

PRONI, Marcelo Weishaupt. Esporte-espetáculo e futebol-empresa. 1998. Tese (Doutorado em Educação Física) - Faculdade de Educação Física, Universidade Estadual de Campinas, Campinas, 1998.

QUERINO, Ana Célia; SILVA, Juvêncio Borges. Diversidade cultural: proteção e tutela na pósmodernidade. Revista Direito e Liberdade, Natal, v. 16, n. 3, p. 11-35, set./dez. 2014. 

PROMOÇ̃̃O CULTURAL PARA O DESENVOLVIMENTO

Quadrimestral.

RECBRASIL. Inovações tecnológicas no futebol. Disponível em: <http://recbrasil.com.br/2014/06/inovacoes-tecnologicas-no-futebol/.>. Acesso em: 22 abr. 2016.

RODRIGUES, Eduardo Fantato; MONTAGNER, Paulo César. Esporte-espetáculo, televisão e pedagogia do esporte: o que crianças compreendem e as relações com um programa esportivo de televisão. Digital Lecturas: Educación Física y Deportes, Buenos Aires, n. 10, v. 85, 2005.

SANTOS, L.M.V. A Evolução da Gestão no Futebol Brasileiro. Dissertação de Mestrado. Fundação Getúlio Vargas/ Escola de Administração de Empresas de São Paulo: São Paulo, 2002.

SILVA, L. M.; GUIMARAES, P. B. V.; SILVA, L. C. . A autonomia das entidades gestoras do futebol brasileiro: viabilidade e limites da intervenção estatal. In: GUIMARÃES, Patrícia Vilar Borba; XAVIER, Yanko Marcius de Alencar. (Org.). Megaeventos e seu impacto jurídico: A Copa do Mundo, Olimpíadas e Desenvolvimento do Brasil. 1ed.São Paulo: Santarém, 2015, v. 1, p. 11-70.

SOARES, Mario Luiz. A miopia do marketing esportivo dos clubes de futebol no Brasil: proposta de um modelo de gestão de marketing esportivo para os clubes brasileiros. 2007. Tese (Doutorado em Administração) - Faculdade de Economia, Administração e Contabilidade, Universidade de São Paulo, São Paulo, 2007.

SÓCIO PALMEIRAS. Associa-se. Disponível em: <https://socio-palmeiras.futebolcard.com>. Acesso em: 14 nov. 2015.

SOUZA, Gabriel Menandro Evangelista de. Adoção do regime de empresa e o futebol profissional. 2005. 82 f. Trabalho de Conclusão de Curso. (Graduação em Direito) - Centro Universitário de Brasília.

TERRA. Da Série A, só três clubes não aderem ao Profut. Ao todo, mais de 100 entram no refinanciamento. Disponível em: <http://verdaoweb.terra.com.br/news.asp?nID=26694>. Acesso em: 16 abr. 2016

TOTALSPPORTEK. Premier League TV Rights Money Distribution (2016-19). Disponível em: <http://www.totalsportek.com/money/premier-league-tv-rights-money-distribution/>. Acesso em: 16 abr. 2016.

TOLEDO, L. H. Pode uma Relação Identitária Encolher? Futebol e Cultura em Tempos de Olimpíadas. In: José Carlos Marques (organizador). (Org.). A copa das Copas: reflexões sobre o mundial de futebol de 2014 no Brasil. 1. ed. São Paulo: Edições Ludens, 2015, v. 1, p. 7-33

UOLESPORTE. Patrocinador do Botafogo faz 'promoção' e muda preço de anúncio na camisa. Disponível em: <http://uolesporte.blogosfera.uol.com.br/2015/03/08/patrocinador-dobotafogo-faz-promocao-e-muda-preco-de-anuncio-na-camisa/>. Acesso em: 14 nov. 2015.

VASCO. Vasco Dívida Zero. Disponível em: <http: / /www.vascodividazero.com.br>. Acesso em: 14 nov. 2015. 
ISSN 1981-3694

(DOI): 10.5902/1981369422402 REVISTA ELETRÔNICA DO CURSD DE

VEJA. Dívida Ativa da União - Clubes de futebol. Disponível em:

<http://veja.abril.com.br/complemento/esporte/pdf/dividas-times-futebol.pdf>. Acesso em: 21 set. 2015

VERMELHO DE PAIXÃO. Mais 100 sacos de cimento para arena. Disponível em:

<http://www.vermelhodepaixao.com.br/2015/02/mais-100-sacos-de-cimento-para-arena.htm>. Acesso em: 14 nov. 2015

Recebido em: 26/05/2016 / Revisões requeridas em: 14/10/2016 / Aprovado em: 25/10/2016 